\title{
Exploring the perception of childbearing barriers in a low fertility subgroup of Iran: a qualitative study
}

Roya Safari-Faramani ${ }^{1}$, Ali Akbar Haghdoost ${ }^{2}$, Mohammad Reza Baneshi ${ }^{3}$, Reza Dehnavieh ${ }^{4}$

${ }^{1} \mathrm{Ph} . \mathrm{D}$. Candidate of Epidemiology, Modeling in Health Research Center, Institute for Futures Studies in Health, Kerman University of Medical Sciences, Kerman, Iran

${ }^{2} \mathrm{Ph} . \mathrm{D}$. of Epidemiology, Professor, HIV/STI Surveillance Research Center, and WHO Collaborating Center for HIV Surveillance, Institute for Futures Studies in Health, Kerman University of Medical Sciences, Kerman, Iran

${ }^{3} \mathrm{Ph} . \mathrm{D}$. of Biostatistics, Associate Professor, Modeling in Health Research Center, Institute for Futures Studies in Health, Kerman University of Medical Sciences, Kerman, Iran

${ }^{4}$ Ph.D. of Health Service Management, Social Determinant of Health Research Center, Institute for Futures Studies in Health, Kerman University of Medical Sciences, Kerman, Iran

Type of article: Original

\begin{abstract}
Background: In Iran, the total fertility rate is 1.8 and it is especially low in highly educated women. Also, there is a considerable difference between the ideal and realized fertility in this sub-population. Clear knowledge on the barriers to achieve the ideal family size is necessary to formulate policies.

Objective: The study aimed at explaining the barriers of childbearing in this sub-population.

Methods: This was a qualitative study using conventional content analysis. The study was conducted from April 2015 to January 2016 across the colleges of Kerman University of Medical Sciences in the southeast of Iran. The study population consisted of $\mathrm{PhD}$ students and faculty members who were studying and working in this university. We used semi-structured interviews to collect data. The sampling procedure was purposeful sampling and it continued until data saturation was achieved. Conventional content analysis was performed to analyze the gathered data.

Results: Twenty two participants took part, all of whom were married and half of whom were women. Eight of the participants were faculty members and the rest were $\mathrm{PhD}$ students. Two categories were extracted, including lake of enabling environment and personal preferences as the main barriers to childbearing in the highly educated subpopulation. Each of the categories included corresponding secondary and primary categories.

Conclusions: Different factors affect childbearing decision making in highly educated people. Taking into account these barriers is important at the time of formulating pro-natalist policies.

Keywords: Fertility, Iran, Qualitative study
\end{abstract}

\section{Introduction}

The fertility pattern in Iran has changed in the recent decades, quite significantly. Nowadays, Iranian couples, in comparison with their parents, prefer late marriages, delayed childbearing and few children $(1,2)$. Iranian women who used to have six to seven children in the late 1970s, today, stop at one or two (1). Although about 95 percent of Iranian couples currently have their first child, the interval between marriage and the first birth has grown longer and also, the number of couples willing to have two or three children has declined (2). Total fertility rate (TFR) is the lowest in educated women in Iran and it seems that there are some obstacles to achieve an ideal family size in this sub population. Based on the latest studies, TFR among Iranian women is 1.8, compared to 1.2 in highly educated women and postgraduates (3). There is a significant difference between desired and realized fertility in this group in Iran. Kazemipour et al. showed that the desired number of children in postgraduates is 2.3 (4). What the obstacles are, to achieve the desired family size in this sub population is so important when we are trying to formulate pro-

\section{Corresponding author:}

Professor Dr. Ali Akbar Haghdoost. Tel: +983433205092, Email: ahaghdoost@gmail.com

Received: April 01, 2017, Accepted: June 12, 2017, Published: June 2018

iThenticate screening: May 16, 2017, English editing: August 12, 2017, Quality control: May 10, 2017

This article has been reviewed / commented by three experts

Funding / research project approval: 90/94

Ethics approval: k/93/583

(C) 2018 The Authors. This is an open access article under the terms of the Creative Commons Attribution-NonCommercialNoDerivs License, which permits use and distribution in any medium, provided the original work is properly cited, the use is non-commercial and no modifications or adaptations are made. 
natalist policies. Education has been considered as a basic element for fertility control. It is one of the main contributing factors on fertility and the role of women (5-7). Education affects fertility in different ways; however, these paths are not fully recognized: avoiding traditional values, accepting the ideas of the modern world, paying more attention to the quality of childcare and welfare of children, changing of the value of having children, cost of opportunity, entering the labor market, and changing of the position of educated women in the household, which empower them to express and implement their decisions (8-11). Educated women, compared to non-educated women, are less willing to assume traditional roles and, furthermore, education opens the windows to the modern world and empowers them to use contraceptives effectively $(5,8)$. Improving the educational level, particularly for women, may help individuals find their place in the family, and seek autonomy and gender equality. MacDonald believes that gender equality is necessary for fertility reduction (12). Moving toward nuclear and child-centered families as well as paying more attention to the quality of the childcare in educated couples, compels them to have a smaller family (13). Education is one of the main driving forces of fertility reduction in Iran. Assessing the history of fertility reduction in Iran reveals that urban couples with higher education were the leading group (3, 14). As Abbasi-Shavazi showed, up to 30 percent of fertility reduction is attributed to improvement in female education (15). Dealing with maternal responsibility is a matter of issue for highly educated or working women particularly in the societies where women have a key role in the care for children and household responsibilities. In the presnce of demanding jobs and absence of supportive family policies, couples are unwilling to have children because of the extra responsibility of having children (16). On the other hand, educational systems are important. Flexible systems that support women to have a child when they are a student and let them return to school after childbirth may facilitate childbearing (16). Based on the literature, policies to reconcile work and family are very important to help women to balance work and family (17). As Mills et al. reported, women want to postpone childbearing until graduation and achievement of occupational and economic stability, due to difficulties in balancing education and maternal responsibilities (11). Iran's government has gone from supporting family planning campaigns and advocating small families to a pro-natalist approach as they try to reverse the fertility decline. The main question of this study is to identify barriers to achieve desired family size in the higly educated sub-groups. To the best of our knowledge, there is no reliable evidence on this topic and we are in need of that when formulating effective policies. With a better understanding of the barriers and socio-economic obstacles to childbearing in this sub-group, more effective policies could be formulated. We aimed at designing a qualitative study due to the opportunity of this method to hear the voice of the people.

\section{Material and Methods \\ 2.1 Study design and setting}

When the goal is to investigate individuals' experiences and points of view, the qualitative approach seems proper (18-20). In this study, a qualitative approach using conventional content analysis was used. The study population consisted of $\mathrm{PhD}$ students and faculty members. The study was conducted from April 2015 to January 2016 across the colleges of Kerman University of Medical Sciences (KMU) in the southeast of Iran. In our study, all the PhD students and faculty members were studying and working in this university. The eligibility criteria included being married, childlessness or having one or two children, being younger than 45 and willingness to participate in this study.

\subsection{Study Procedures}

Sampling procedure was purposeful and it continued until the data saturation was achieved. We reached data saturation after the 17 semi-structured interviews and one focus group discussion $(5 \mathrm{PhD}$ students participated in focus group discussion). In total, $22 \mathrm{PhD}$ students and faculty members participated in the study. We found the cases based on their demographic characteristics. One of the research team members (RSF) contacted four out of the seven colleges of KMU. She compiled a list of the eligible participants. At first, we approached them by direct contact. Then we describe the study objectives and we asked them to participate in the study. If they desired to participate, we made an appointment to conduct the interview. Both semi-structured interviews and focused group discussions were used to collect the data (19). Interviews were conducted by RSF and she was also the coordinator of the focus group discussion. The main question was around their viewpoints about barriers of childbearing in a highly educated population. We asked them: What is the main reason for educated couples to avoid childbearing? How do you think about educated couples' barriers to childbearing? Exploratory questions were asked to better explain the topic. In the case of faculty members, interviews took place in their offices and in the case of PhD students, the interviews were conducted in a private room located in their college. The interviews were in Persian. Interviews lasted 27 minutes on average. As focus group discussion is a way to collect data, provide a good opportunity to exchange knowledge, ideas and opinion, we decided to run a focus group discussion on eligible participants at the end of the individual 
interviews to ensure data saturation. Focus group discussion was conducted in one session. The RSF was the coordinator. The duration of focus group discussion was 80 minutes. Verbal consent was obtained from all participants before the interviews began and the interviews were recorded by permission of the participants. Verbatim transcriptions were carried and RSF checked all the transcribed interviews in order to prepare for analysis.

\subsection{Data Analysis}

We used a qualitative conventional content analysis approach for analyzing the data (21). The interview transcriptions were read several times. We considered each interview as a unit of analysis. Then meaning units were explored. After condensing the meaning units and labelling a code, all the similar codes were categorized in primary categories. Similar primary categories were gathered and secondary categories emerged. Finally, the main categories were extracted. Data analysis started soon after the first interview and continued for three months after the sampling was completed.

\subsection{Trustworthiness}

We used the criteria of credibility, dependability, confirmability, and transferability to assess trustworthiness (22, 23). Member check was used to confirm credibility. After data collection and primary data analysis, the results were presented to 10 of the participants who were asked to read and confirm the results. Credibility was also ensured by prolonged engagement. Confirmability was achieved by conducting all the steps of the study, from conception of the idea to writing the results, under the supervision of the teachers and experts of qualitative studies. These teachers were among the ones who were experienced in qualitative studies. To increase the transferability of the study, we tried to clearly describe all the steps of the study. The research team members held several sessions to check the findings, and the results were checked by an expert in qualitative research method.

\subsection{Ethics considerations}

The Ethical Committee of Kerman University of Medical Sciences approved the research proposal (Ref. no.: k/93/583). All participants provided verbal consent to participate and for publication of their de-identified information. We explained the study to the participants clearly and asked them to designate a time for the interview, if they agreed. If any one of the participants did not want to take part, he/she could inform us at any time. There were two cases who refused, one of them a faculty member and the other, a student. We assured them about confidentiality and anonymity and allowed them to leave the interview when they wanted to. In the focus group discussion, as we could not ensure the participants' confidentiality and anonymity, we ensured informed consent and allowed leaving the study at the participants' request.

\section{Results}

Twenty two participants entered the study. All of whom were married and half of whom were female. Eight participants were faculty members and the rest were PhD students. Participants' age varied between 28 and 43 years and nine participants were older than 35. Nine participants were childless. The focused group discussion was held in one session where five $\mathrm{PhD}$ students attended. Focus group discussion lasted 80 minutes. We extracted two categories, including lake of enabling environment and personal preferences as the main barriers to childbearing in the highly educated subpopulation. Each of the categories included some secondary categories. The extracted categories and corresponding secondary and primary categories are presented in Table 1.

Table 1. Extracted categories, secondary and primary categories' barriers to childbearing in Iranian educated sub-population

\begin{tabular}{|l|l|l|}
\hline Categories & Secondary categories & Primary categories \\
\hline \multirow{3}{*}{$\begin{array}{l}\text { Lake of enabling } \\
\text { environment }\end{array}$} & $\begin{array}{l}\text { Incompatibility between work and } \\
\text { family for educated women }\end{array}$ & High workload \\
\cline { 3 - 3 } & & Inadequate facilities for parents \\
\cline { 2 - 3 } & Cultural issues & Problems with child caring \\
\hline \multirow{2}{*}{ Personal preferences } & Childbearing postponement & Preferring social roles to maternal roles among girls \\
\cline { 3 - 3 } & & $\begin{array}{l}\text { Pate marriage, infertility and high risk pregnancy } \\
\text { fostponing childbearing to a better situation, }\end{array}$ \\
\cline { 2 - 3 } & Idealism & Self-fulfillment in educated people \\
& & Paying more attention to the quality of child caring \\
& Worry about the future \\
\hline
\end{tabular}




\subsection{Lake of enabling environment}

One of the main categories was lake of enabling environment. It refers to the environmental factors that facilitate raising a child. Secondary categories in this category were: Incompatibility between work and family for educated women, and cultural issues.

\subsubsection{Incompatibility between work and family for educated women}

Trying to keep a balance between work and family was one of the main important issues. This secondary category consists of three primary categories including: high workload, inadequate facilities for parents, and problems with childcare.

\subsubsection{High workload}

Most of the participants complained about high mental duress, high workload, and insufficient time for childcare. Both men and women believed that educated groups are so busy that they cannot allocate time for thinking about childbearing. Furthermore, they talked about intrinsic interest in childbearing, and emphasized that a competitive atmosphere should have profited women. Also, they demanded a decrease in the duration of working hours of women or increased annual leave for mothers. A 40 -year-old woman, a faculty member with no children said:

“...Once I was talking with one of my colleagues, who is a psychologist herself. I said I didn't feel the absence of a child in my life so I didn't think of having one. That is because I'm really busy, maybe there should be more free time for faculty members, as we are too busy..." $(\mathrm{p}-10)$

3.1.1.2. Problems with child caring

Most of the participants, especially women, were dissatisfied with the childcare facilities provided by their workplace, and mentioned it as a cause for the mother's stress and worry. A 36-year-old woman, a faculty member with two children said: "...I wish there was a nursery right here where I could go and breast feed my baby then I wouldn't be worried whether my baby was hungry or not, so my baby wouldn't be bottle fed..." (p -13)

In addition to lack of a nursery, the participants complained of poor childcare services. Most of them believed that finding a reliable baby sitter is not easy and basically, there is no specific organization which can help them find a suitable baby sitter. Most of the time, these baby sitters are sought out through acquaintance networks, therefore, no organizations control them.

\subsubsection{Cultural issues}

Cultural issues refer to cultural determinants of childbearing decision making such as the norms and attitudes. This secondary category consists of two primary categories, which included cultural unacceptability of large families and preferring social roles to maternal roles among girls.

\subsubsection{Cultural unacceptability of large families}

Participants stated that since implementing the anti-natalist policies, the small family norm has prevailed among Iranians, meaning that large families are no longer socially acceptable. Sometimes the relatives have to force the couples to have a child. There has always been fear of not being accepted by society among educated people. They stated that having many children is not a norm, especially among educated people and faculty members. A 30 -yearold woman, a PhD student with a child said: "...Nowadays, if someone who has two kids plans for the third one, others laugh at her, so maybe some won't think of childbearing for fear of being teased..." (p -5)

3.1.2.2. Preferring social roles over maternal roles among girls

Some of the participants pointed out that since our mothers had many children, they always held this idea that a social position is much desirable for girls than childbearing. A 32-year-old woman, a $\mathrm{PhD}$ student with no children said: "...In the past, there was this saying that a girl will be a babysitter finally, but our moms answered strictly that their daughter would not be a babysitter, she would be a doctor or engineer someday and take a nanny to care for her children..."(p-11). Some of the participants complained that our social structures are not proper for training mothers and fathers. Also, the heavy competitive atmosphere prevailing in the educational system is not designed to educate mothers and fathers.

\subsection{Personal preferences}

Another extracted category was personal preferences. This category is about personal barriers which influence the decision on childbearing. It consists of two secondary categories including: childbearing postponement and idealism. 3.2.1. Childbearing postponement

Postponing childbearing was one of the main secondary categories. It is influenced by late marriage and also waiting for a suitable opportunity. This secondary category consists of two primary categories including: Late marriage and postponing childbearing for a better situation, financial stability, and getting along with each other.

\subsubsection{Late marriage}

As viewed by the participants, the educated population postpones their marriage due to education. This may originate from the idea that they can find a better job when they achieve higher degrees. So, late marriage, especially 
for women, might result in infertility and high-risk pregnancy. A 30-year-old woman, a PhD student with a child said: “...Continuing studies, by itself, increases the age of marriage, but with no education, girls at home get married at the age of 20 or 30; finally they will marry. Educated women must participate in the entrance exams of Bachelor's, Master's, and PhD, saying they are stressful, they have to study, they don't want to marry anymore, and when they get older, over 30 for example, they won't have a chance to have a baby..." (p -5)

3.2.1.2. Postponing childbearing for a better situation, financial stability, and getting along with each other

On the other hand, as the participants maintained, educated couples who marry late may want to spend time for getting to know each other and creating a stable financial situation. Since they don't have enough time for childbearing, they stop at one. A 32-year-old woman, a PhD student, with no children, said: “...My husband says: we don't want children until our life becomes stable, and of course we need to know if we can get along with each other before bringing another person into this world, we need to match with each other since we are newly married..." (p - 11). A 27-year-old woman, a PhD student, with a child, said: “...The money situation is also something, but with today's expenses, child caring is impossible. Take my sister, for example, they do not want to have children until their living expenses decrease somehow. Having a baby is expensive, you know..." (p -10)

3.2.2. Idealism

Another secondary category was idealism. It refers to ideational norms and attitudes influencing on childbearing decision making. This secondary category consists of three primary categories including: self-fulfillment in educated people, paying more attention to the quality of child caring, and an unclear future for the children.

3.2.2.1. Self-fulfillment in educated people

Most of the participants stated that self-fulfillment is one of the main barriers for childbearing in educated groups. They believed that educated people allocate most of their time to studying, and when they want to enjoy the fruits of their labor, in spite of their desire, they must take care of their children. Therefore, they prefer having no children or, otherwise, stop at one. A 40-year-old man, a faculty member with a child said: “...Imagine a man and his wife who are both physicians, the man is at work in the mornings and evenings. Now don't you think it is kind of hard for the wife to stay at home baby sitting or taking the child to language classes or swimming in the evening? She likes to be socially active instead of staying at home and taking care of the kids, who no one knows what he/she will become in the future..." (p-1)

\subsubsection{Paying more attention to the quality of children}

Most of the participants stated that the motivation for raising children properly moved them towards having a single child. In fact, they prefer to have few children, and in return bring them up in the best way possible. A 34-year-old woman, a faculty member with a child said: “...Maybe they [educated couples] think of childbearing with more sympathy or more plans, meaning that they don't think: 'ok, the baby comes and finally grows up'; they think of the quality of growing up, how it would be..." (p -2)

\subsubsection{Unclear future for the children}

Worries about the children's future were another concern, expressed by most of the participants. A 40-year-old man, a faculty member with a child said: “...I believe there is always a question mark about the kid's future. Many wealthy people are always concerned about whether their kid may get into trouble in the future. It is like that in our country, so that even for that only child, they sometimes think it was a big mistake having brought him into this world, because his future is not clear..." ( $p-7)$. Most of the participants were worried about their children's job in the future. They stated that the government's function in providing jobs for the youth is poor and, in practice, people must endeavor to get a job on their own. In this situation, having fewer children is better.

\section{Discussion}

Based on the results of this study, several factors can influence decision making for childbearing. In addition to high-pressured working situations for mothers, lack of proper childcare facilities and effective pro-natalist policies result in a difficult situation for mothers to keep a balance between work and the family. This is particularly important in such a traditional society as Iran where women shoulder the greater burden of the caring responsibilities. In this situation, as McDonald stated, women try to limit the number of children (12). On the other hand, the mother spends a large proportion of the day at the workplace. In the absence of such child-caring facilities, the mother's problems are exacerbated by stress and anxiety, and this finally leads to undesirable experiences, so naturally affects the decision of individuals for having more children. In agreement with our results, Rachel Margolis showed that disruption of a parent's welfare after their first birth will affect the decision for the next child (24). Although childbearing is well accepted in Iranian culture, nowadays, having a small family is turning into a social norm. It seems that the slogan of 'fewer children equals a better life and more resources' has been a dominant worldview. In other words, a large family is disapproved of by the people, particularly in the case of educated couples. As educated women were the pioneers of fertility reduction, in the case of highly educated couples, people 
expect a small family and limited number of children. This may influence educated couples' decisions. This finding is similar to other studies. In a study by Kazemipour et al. on thirteen thousand young adults on the eve of marriage, 80 percent of the participants believed that having children strengthens the family, however, around one third of the participants believed that if they had more than two children, they would be reprehended by others (4). Around half of the population in this study were graduated.

Preferring social participation was one of the barriers in our study. As Basu et al. points out, literacy brings not only the power of reading and writing, but it also may help achieve more autonomy, gender equality, ideas of the modern world, and also individualism (8). Higher education, higher autonomy, and modernization are known as the main causes of fertility decline in Iranian women $(25,26)$. Also, education is a way to better social class status in Iran (27). Mothers strongly recommended that their daughters should continue education and attend university. This highlights the social roles for women and may result in ignorance of women's role. Kazemipour et al. reported that approximately one fifth of the participants believed that educational and occupational progress is more important than childbearing (4). In other words, women who have social roles are becoming more popular. In the present study, the participants highlighted the encouraging roles of their mothers for getting involved in society, and confirmed the findings of a Benzies et al. study (28). On the other hand, women who were willing to receive higher educational degrees were more reluctant to accept traditional maternal roles, including early marriage and childbearing $(5,29)$. Therefore, it is necessary to prepare the situation to promote the fact that improving one's social position does not necessarily entail ignoring women's roles mainly to the responsibilities related to the house and rearing the children.

The findings of the present study highlight that the worries of a small subgroup of an educated population is not very different from other groups. Findings confirm that educated people pay more attention to the quality of the children, how their children are brought up and their future. In the present study, concerns about the children's future was one of the main worries of parents. Roughly half of the participants in the study by Kazemipour et al. also pointed to concerns about the future as an impediment for childbearing (4). In addition, Karimian et al., in their study on 22 pregnant women, reported worries about the future of their children as the main contributing factor for childbearing decision making (30). This study is good evidence on the barriers of childbearing in a highly educated subgroup, and provides a worthwhile knowledge for formulating effective policies. We used a qualitative approach, but now hearing from the population is interesting evidence. Conducting large studies across the country is recommended. Also, we entered just a small sub-group of an educated population. Exploring the viewpoints of other sub-groups such as specialists is recommended.

\section{Conclusions}

Based on the results of the presented study, several factors are likely to influence childbearing decision making. Three main categories included infrastructural problems, social barriers, and personal factors. Taking these barriers into account is important at the time of formulating pro-natalist policies. Knowing barriers of childbearing in this sub-population is required, to formulate more proper policies. More study on the motives and barriers of childbearing decision making is recommended.

\section{Acknowledgments:}

This study is a part of $\mathrm{PhD}$ thesis; our grateful thanks go to all who participated in this study and also Kerman University of Medical Sciences for their support. The proposal of the research was approved by Kerman University of Medical Sciences and the code for approved research project was 90/94.

\section{Conflict of Interest:}

There is no conflict of interest to be declared.

\section{Authors' contributions:}

All authors contributed to this project and article equally. All authors read and approved the final manuscript.

\section{References:}

1) McDonald P, Hosseini-Chavoshi M, Abbasi-Shavazi MJ, Rashidian A. An assessment of recent Iranian fertility trends using parity progression ratios. Demographic Research. 2015; 32(58): 1581-602. doi: 10.4054/DemRes.2015.32.58. 
2) Hosseini-Chavoshi M, McDonald P, Abbasi-Shavazi MJ, Rashidian A. Tempo and quantum of fertility in Iran: An Application of the Synthetic Parity Progression Ratio Method. XXVII IUSSP International Population Conference; 2013.

3) Eyni-Zeynab H, Soltani Z, Shams-Ghahfarokhi F, Shiri M, Eslami M, Motlagh ME. The multivariate study of the changes in fertility trend in Iran. Tehran: Statistical Research and Training Center. 2015. Available frrrom: http://www.srtc.ac.ir/en/ResearchPlan/DetailView/258/.html.

4) Kazemipour S, Zahedian A, Safakish M, Rezaei-Ghahroudi Z, Eslami M, Eyni-Zeynab H, et al. Attitudes of youths on the verge of marriage and 15-49 married women on childbearing and examine influential cultural, societal and economic factors on it. Tehran: Statistical Research and Training Center. 2015. Available from: http://www.srtc.ac.ir/en/ResearchPlan/DetailView/206/.html.

5) Rindfuss RR, Bumpass L, St John C. Education and fertility: implications for the roles women occupy. American sociological review. 1980; 45(3): 431-47. doi: 10.2307/2095176. PMID: 7406358.

6) Cleland J. Education and future fertility trends, with special reference to mid-transitional countries. UN Population Bulletin. 2002.

7) Baker DP, Leon J, Smith Greenaway EG, Collins J, Movit M. The Education Effect on Population Health: A Reassessment. Population and Development Review. 2011; 37(2): 307-32. doi: 10.1111/j.17284457.2011.00412.x.

8) Basu AM. Why does education lead to lower fertility? A critical review of some of the possibilities. World Development. 2002; 30(10): 1779-90. doi: 10.1016/S0305-750X(02)00072-4.

9) Davia MA, Legazpe N. Educational attainment and maternity in Spain: not only "when" but also "how". Review of Economics of the Household. 2015; 13(4): 871-900. doi: 10.1007/s11150-014-9249-6.

10) McDonald P. Theory pertaining to low fertility. International Perspectives on Low Fertility: Trends, Theories and Policies. Tokyo; 2001.

11) Mills M, Rindfuss RR, McDonald P, Te Velde E. Why do people postpone parenthood? Reasons and social policy incentives. Human reproduction update. 2011; 17(6): 848-60. doi: 10.1093/humupd/dmr026. PMID: 21652599; PMCID: PMCPMC3529638.

12) McDonald P. Gender equity in theories of fertility transition. Population and Development Review. 2000; 26(3): 427-39. doi: 10.1111/j.1728-4457.2000.00427.x.

13) Ni Bhrolchain M, Beaujouan E. Fertility postponement is largely due to rising educational enrolment. Population studies. 2012; 66(3): 311-27. doi: 10.1080/00324728.2012.697569. PMID: 22889178; PMCID: PMC3479627.

14) Aghajanian A, Agha H, Gross AB. Cumulative fertility in Iran. Journal of Comparative Family Studies. 1996; 27(1): 59-72.

15) Abbasi-Shavazi MJ, Lutz W, Hosseini-Chavoshi M, KC S. Education and the world's most rapid fertility decline in Iran. International Institute or Applied Systems Analysis. 2008.

16) Rindfuss RR, Choe MK. Diversity across Low-Fertility Countries: An Overview. Low and Lower Fertility: Variations across Developed Countries. Cham: Springer International Publishing. 2015: 1-13. doi: 10.1007/978-3-319-21482-5.

17) Luci-Greulich A, Thévenon O. The Impact of Family Policies on Fertility Trends in Developed Countries. European Journal of Population / Revue européenne de Démographie. 2013; 29(4): 387-416. doi: 10.1007/s10680-013-9295-4.

18) Malterud K. Qualitative research: standards, challenges, and guidelines. Lancet. 2001; 358(9280): 483-8. doi: 10.1016/s0140-6736(01)05627-6. PMID: 11513933.

19) Pope C, Mays N. Qualitative research in health care: Blackwell Publishing Ltd; 2006.

20) Speziale HS, Streubert HJ, Carpenter DR. Qualitative research in nursing: Advancing the humanistic imperative: Lippincott Williams \& Wilkins; 2002.

21) Graneheim UH, Lundman B. Qualitative content analysis in nursing research: concepts, procedures and measures to achieve trustworthiness. Nurse education today. 2004; 24(2): 105-12. doi: 10.1016/j.nedt.2003.10.001.

22) Guba EG. Criteria for assessing the trustworthiness of naturalistic inquiries. Educational Technology Research and Development. 1981; 29(2): 75-91. doi: 10.1007/BF02766777.

23) Lincoln YS. Emerging criteria for quality in qualitative and interpretive research. Qualitative inquiry. 1995; 1(3): 275-89. doi: 10.1177/107780049500100301.

24) Margolis R, Myrskylä M. Parental Well-being Surrounding First Birth as a Determinant of Further Parity Progression. Demography. 2015; 52(4): 1147-66. doi: 10.1007/s13524-015-0413-2. 
25) Abbasi-Shavazi M, McDonald P, Hosseini-Chavoshi M. Women's Autonomy and Fertility Behaviour. The Fertility Transition in Iran: Revolution and Reproduction. Dordrecht: Springer. 2009: 163-77. doi: 10.1007/978-90-481-3198-3 9.

26) Abbasi-Shavazi MJ, Torabi F. Women's Education and Fertility in Islamic Countries. Population Dynamics in Muslim Countries: Assembling the Jigsaw. Berlin, Heidelberg: Springer Berlin Heidelberg. 2012: 43-62. doi: 10.1007/978-3-642-27881-5_4.

27) Abbasi-Shavazi M, McDonald P, Hosseini-Chavoshi M. The Fall in Iranian Fertility: Theoretical Considerations. The Fertility Transition in Iran: Revolution and Reproduction. Dordrecht: Springer Netherlands; 2009: 1-16. doi: 10.1007/978-90-481-3198-3 1.

28) Benzies K, Tough S, Tofflemire K, Frick C, Faber A, Newburn-Cook C. Factors influencing women's decisions about timing of motherhood. Journal of obstetric, gynecologic, and neonatal nursing: JOGNN. 2006; 35(5): 625-33. doi: 10.1111/j.1552-6909.2006.00079.x. PMID: 16958718.

29) Cooke A, Mills TA, Lavender T. Advanced maternal age: Delayed childbearing is rarely a conscious choice: A qualitative study of women's views and experiences. International Journal of Nursing Studies. 2012; 49(1): 30-9. doi: 10.1016/j.ijnurstu.2011.07.013.

30) Kariman N, Simbar M, Ahmadi F, Vedadhir AA. Concerns about one's own future or securing child's future: paradox of childbearing decision making. Scientific Research. 2014; 2014. doi: 10.4236/health.2014.610128. 